\title{
EVALUASI DATABASE SENJATA UNTUK SISTEM KEAMANAN MENGGUNAKAN FUZZY LOGIC
}

\author{
Dwi Febri Chandra Kusuma, Dwi Arman P, Fajar Kholid, Irfan Mujahidin \\ Jurusan Teknik Elektro UNMER Malang \\ Departemen Elektronika LEMJIANTEK Malang \\ e-mail: dwifebri@gmail.com
}

\begin{abstract}
Abstrak
Evaluasi Database Senjata Untuk Sistem Keamanan Menggunakan Fuzzy Logic ini dibuat untuk memberikan ID pada setiap senjata sehingga ketika terjadi penyalahgunaan senjata dapat segera ditelusuri siapa penanggung jawab atas senjata tersebut. Selain itu juga untuk membuat sistem administrasi senjata secara otomatis sehingga akan menimbulkan efisiensi waktu serta kemudahan dalam proses peminjaman dan pengembalian senjata pada gudang senjata di jajaran $T N I-A D$. Sistem yang dibuat menggunakan perangkat keras berupa Fingerprint Scanner, RFID Reader, RFID Tag, Laptop, dan model senjata serta dengan menggunakan metode fuzzy logic.
\end{abstract}

Kata Kunci: Database, Fingerprint Scanner, RFID.

\section{Pendahuluan}

Dengan kemajuan teknologi yang sudah sangat canggih saat ini akan lebih baik jika sistem keamanan senjata dievaluasi guna meminimalisir celah keamanan yang ada dengan memberikan ID pada setiap senjata. Dengan pemberian ID ini maka apabila terjadi penyalahgunaan senjata dapat segera ditelesuri siapa yang bertanggung jawab atas senjata tersebut[1][2]. Selain itu dengan pemberian ID pada senjata maka proses pencatatan keluar masuk senjata pada gudang senjata menjadi lebih mudah dan efisien.

Sistem pencatatan administrasi keluar masuk senjata pada jajaran TNI-AD yang ada saat ini masih manual. Sehingga sangat tidak efisien karena akan membuat pergerakan pasukan menjadi terhambat[3][4]. Selain itu dengan belum adanya ID pada setiap senjata, maka akan menimbulkan celah keamanan pada saat pengambilan senjata dimana seorang personel dapat mengambil senjata yang bukan pegangannya. Hal ini dapat menimbulkan terjadinya penyalahgunaan senjata. Maka jika pada senjata tidak memiliki ID dan terjadi penyalahgunaan senjata akan membutuhkan waktu untuk menelusuri personel yang bertanggung jawab atas senjata tersebut[5].

Teknologi RFID dan fingerprint scanner dapat dimanfaatkan untuk penyempurnaan sistem administrasi senjata. Nomor ID dari RFID Tag digunakan untuk memanggil data senjata yang telah tersimpan pada database. Fingerprint scanner digunakan sebagai pengaman guna mengkonfirmasi sesuai tidaknya pengambil senjata dengan data personel yang terdapat pada database[6][7]. Dengan pertimbangan di atas, untuk itu perlu dibuat sebuah sistem Evaluasi Database Senjata Untuk Sistem Keamanan Menggunakan Fuzzy Logic.

\section{Metode penelitian}

Untuk mempermudah sebuah perancangan alat maka diperlukan sebuah rancangan. Rancangan tersebut berupa blok diagram sistem secara global. 


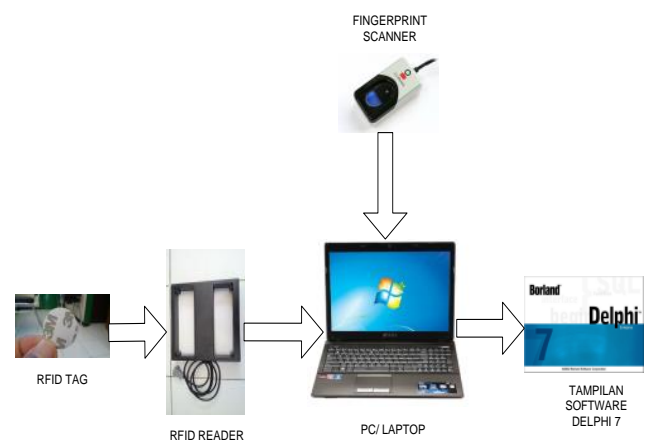

Gambar 2.1 Blok Diagram Sistem

Pada Gambar 4 diatas adalah gambar blok diagram dari keseluruhan dari sistem yang dibuat

Fingerprint Scanner yang digunakan pada sistem ini adalah tipe U.are.U 4500. Pada perangkat ini telah tertanam sistem fuzzy logic. Fuzzy logic dalam perangkat ini sangat berguna pada saat pembacaan sidik jari[8][9]. Dalam hal ini, sebagai contoh pada saat melakukan registrasi. Maka sistem ini akan meminta 4 (empat) kali pemindaian sidik jari untuk setiap satu jari yang akan disimpan ke dalam database dan pada saat pemindaian ini fuzzy logic sangat dibutuhkan untuk membedakan apakah sidik jari pada pemindaian pertama dengan pemindaian-pemindaian berikutnya memiliki kemiripan[10].

RFID Tag yang akan digunakan dalam sistem ini yaitu RFID Tag dengan jenis koin[11][12].

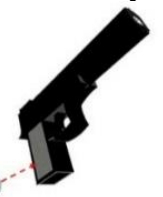

Gambar 2.2 Peletakkan RFID Tag Pada Senjata

Pemilihan Tag jenis koin ini dimaksudkan untuk memudahkan pada saat penyematan ke dalam senjata, disamping itu juga agar Tag tersebut lebih aman karena akan sangat sulit untuk terlepas dari senjata[13][14].

Perencanaan sotware program yang digunakan adalah bahasa pemrograman Delphi 7.0.

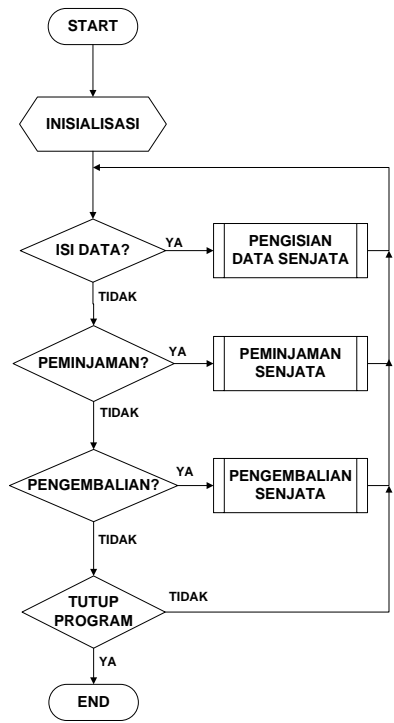

Gambar 2.3 Flowchart Keseluruhan

Pada Gambar 6 merupakan flowchart yang menggambarkan cara kerja secara keseluruhan dari perencanaan sistem yang dibuat. 
Pada proses ini, senjata yang belum berisi data di daftarkan oleh petugas gudang senjata. Pendaftaran ini bertujuan untuk melakukan proses pengisian data ke dalam database[15][16]. Adapun flowchart pengisian data senjata ditunjukkan dalam Gambar.7.

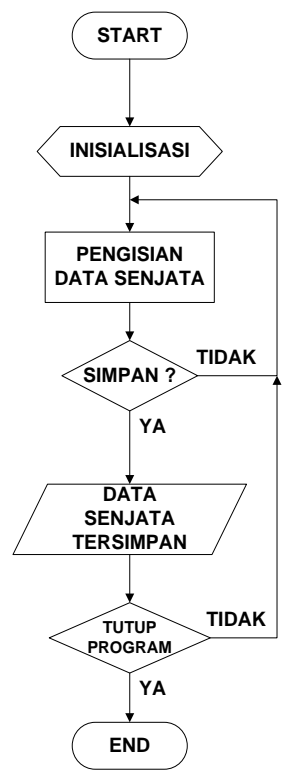

Gambar 2.4 Flowchart Pengisian Data Senjata

Data dalam database ini yang akan dipaggil ketika RFID Reader mendeteksi Tag yang telah disematkan ke dalam senjata. Data yang diisikan yaitu berupa jenis senjata, nomor senjata, serta data-data diri dari pemegang senjata tersebut yaitu berupa nama, pangkat, NRP, dan sidik jari[17][18].

Apabila senjata sudah terdaftar di database maka ketika senjata terbaca oleh RFID Reader dan jika senjata tersebut tercatat berada di dalam gudang maka akan dapat tercatat tanggal dan jam pengambilan senjata. Namun sebelum waktu keluar senjata tercatat, sistem ini membutuhkan konfirmasi dari sidik jari peminjam senjata[19][20]. Sidik jari ini diperlukan guna mensinkronkan antara data sidik jari peminjam senjata dengan data sidik jari pemegang senjata yang telah tersimpan pada database.

Ketika personel telah selesai menggunakan senjata, maka personil tersebut wajib mengembalikan senjata yang telah dipakai tersebut ke gudang senjata. Bukan hanya pada saat pengambilan, pada saat proses pengembalian senjata juga harus sesuai dengan prosedur sehingga senjata yang sudah dikembalikan dapat tercatat waktu kembalinya. Pada saat proses pengambalian senjata, konfirmasi sidik jari dari peminjam senjata[21][22]. Namun untuk mengantisipasi hal yang diinginkan yang mengakibatkan personel peminjam senjata tidak bisa langsung mengembalikan senjata ke gudang, maka konfirmasi sidik jari dapat dilakukan oleh petugas gudang senjata sehingga senjata tetap bisa dikembalikan lagi ke dalam gudang. Pada Gambar 7 ditampilkan gabungan flowchart peminjaman dan pengembalian senjata. 


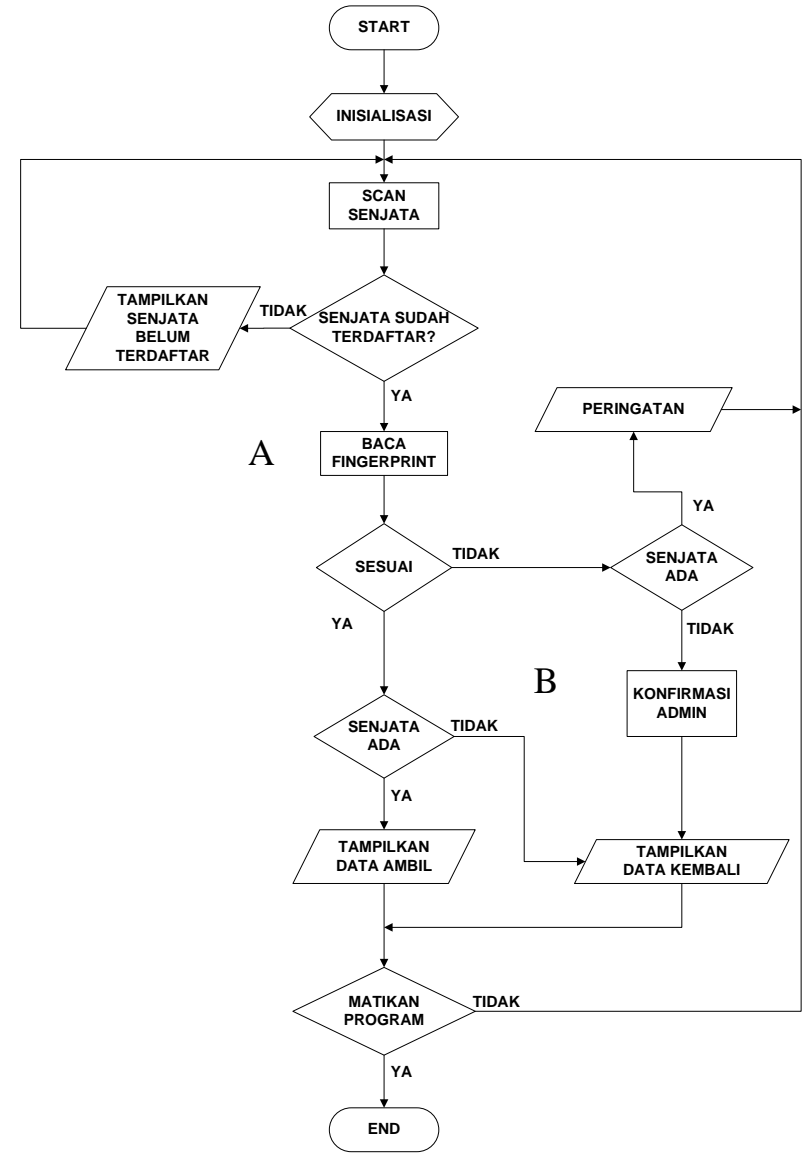

Gambar 2.5 Flowchart Peminjaman dan Pengembalian Senjata

Pada Gambar 7 ditunjukkan flowchart peminjaman dan pengembalian senjata[23][24]. Daerah yang diberi huruf $A$ pada flowchart tersebut merupakan bagian dari peminjaman senjata, sedangkan daerah yang diberi huruf $B$ merupakan bagian dari pengembalian senjata.

\section{Hasil dan Analisis}

Data analisa form login ditunjukkan pada Tabel 3 berikut.

Tabel 3.1 Data Analisa Form Login

\begin{tabular}{|c|c|c|c|c|c|}
\hline Tombol & $\begin{array}{c}\text { Jumlah } \\
\text { Percobaan }\end{array}$ & Berhasil & Gagal & Berhasil & Gagal \\
\hline Login & 20 & 20 & 0 & 100 & 0 \\
\hline Log off & 20 & 20 & 0 & 100 & 0 \\
\hline
\end{tabular}

Dari Hasil pengujian dapat disimpulkan jika tombol login dan logout pada sistem ini dapat bekerja dengan baik.

Data analisa dari pengisian data senjata dapat ditunjukkan dalam Tabel 4 berikut.

Tabel 3.2 Data Pengujian Input Data Senjata

\begin{tabular}{|c|c|c|c|c|c|c|}
\hline Fungsi & $\begin{array}{c}\text { Jumlah } \\
\text { Percobaan (x) }\end{array}$ & Sukses & Gagal & $\begin{array}{c}\text { Persentase } \\
\text { Keberhasilan } \\
(\%)\end{array}$ & $\begin{array}{c}\text { Persentase } \\
\text { Kegagalan } \\
(\%)\end{array}$ & Keterangan \\
\hline $\begin{array}{c}\text { Upload } \\
\text { Foto }\end{array}$ & 100 & 100 & - & 100 & 0 & $\begin{array}{c}\text { Berjalan } \\
\text { dengan baik }\end{array}$ \\
\hline Simpan & 100 & 100 & - & 100 & 0 & $\begin{array}{c}\text { Berjalan } \\
\text { dengan baik }\end{array}$ \\
\hline Batal & 100 & 100 & - & 100 & 0 & $\begin{array}{c}\text { Berjalan } \\
\text { dengan baik }\end{array}$ \\
\hline
\end{tabular}




\begin{tabular}{|c|c|c|c|c|c|c|}
\hline Fungsi & $\begin{array}{c}\text { Jumlah } \\
\text { Percobaan (x) }\end{array}$ & Sukses & Gagal & $\begin{array}{c}\text { Persentase } \\
\text { Keberhasilan } \\
(\%)\end{array}$ & $\begin{array}{c}\text { Persentase } \\
\text { Kegagalan } \\
\text { (\%) }\end{array}$ & Keterangan \\
\hline Edit & 100 & 100 & - & 100 & 0 & $\begin{array}{c}\text { Berjalan } \\
\text { dengan baik }\end{array}$ \\
\hline Hapus & 100 & 100 & - & 100 & 0 & $\begin{array}{c}\text { Berjalan } \\
\text { dengan baik } \\
\text { Berjalan } \\
\text { Registra } \\
\text { tion } \\
\text { (Finger) }\end{array}$ \\
\hline dengan baik
\end{tabular}

Dari hasil pengujian dapat disimpulkan bahwa penyimpanan data senjata dapat berfungsi dengan baik hanya saja mengalami sedikit kendala pada saat proses registrasi sidik jari[25][26].

Data analisa dari peminjaman senjata dapat ditunjukkan dalam Tabel 5 berikut.

Tabel 3.3 Data Pengujian Peminjaman Senjata

\begin{tabular}{|c|c|c|c|c|c|c|}
\hline Fungsi & $\begin{array}{c}\text { Jumlah } \\
\text { Percobaan } \\
(\mathbf{x})\end{array}$ & Sukses & Gagal & $\begin{array}{c}\text { Persentase } \\
\text { Keberhasilan } \\
(\%)\end{array}$ & $\begin{array}{c}\text { Persentase } \\
\text { Kegagalan } \\
(\%)\end{array}$ & $\begin{array}{c}\text { Kete } \\
\text { rangan }\end{array}$ \\
\hline Baca & 100 & 100 & 0 & 100 & 0 & $\begin{array}{c}\text { Berjalan } \\
\text { dengan } \\
\text { baik }\end{array}$ \\
\hline RFID & 100 & 97 & 3 & 97 & 3 & $\begin{array}{c}\text { Berjalan } \\
\text { dengan }\end{array}$ \\
\hline Pindai & $10 . .$. & & & & &
\end{tabular}

Dari hasil pengujian dapat disimpulkan bahwa peminjaman senjata dapat berfungsi dengan baik hanya saja mengalami sedikit kendala pada saat proses pemindaian sidik jari.

Data analisa dari peminjaman senjata dapat ditunjukkan dalam Tabel 6 berikut[27][28].

Tabel 3.4 Data Pengujian Pengembalian Senjata

\begin{tabular}{|c|c|c|c|c|c|c|}
\hline Fungsi & $\begin{array}{c}\text { Jumlah } \\
\text { Percobaan } \\
(\mathbf{x})\end{array}$ & Sukses & Gagal & $\begin{array}{c}\text { Persentase } \\
\text { Keberhasilan } \\
(\%)\end{array}$ & $\begin{array}{c}\text { Persentase } \\
\text { Kegagalan } \\
(\%)\end{array}$ & $\begin{array}{c}\text { Keteran } \\
\text { gan }\end{array}$ \\
\hline Baca RFID & 100 & 100 & 0 & 100 & 0 & $\begin{array}{c}\text { Berjalan } \\
\text { dengan } \\
\text { haik }\end{array}$ \\
\hline $\begin{array}{c}\text { Pindai sidik } \\
\text { jari }\end{array}$ & 100 & 97 & 3 & 98 & 2 & $\begin{array}{c}\text { Berjalan } \\
\text { dengan } \\
\text { baik }\end{array}$ \\
\hline
\end{tabular}

Dari hasil pengujian dapat disimpulkan bahwa pengembalian senjata dapat berfungsi dengan baik hanya saja mengalami sedikit kendala pada saat proses pemindaian sidik jari.

\section{Simpulan}

Dari penelitian yang telah dilaksanakan, dapat disimpulkan bahwa:

1. Metode fuzzy logic Tsukamoto dapat implementasikan dalam sistem yang dibuat.

2. RFID dan fingerprint dapat dikombinasikan dalam sistem sehingga meningkatkan akurasi data pada saat proses peminjaman dan pengembalian senjata guna meminimalisir celah keamanan.

3. Efisiensi waktu yang dihasilkan pada proses peminjaman dan pengembalian senjata meningkat menjadi sekitar 20 detik setiap orang, sehingga apabila dalam satu kompi dengan jumlah personel 122 orang (Kompi Zipur) maka akan menghemat waktu sekitar 40 menit.

\section{References}

[1] X. Zhang, X. Li, and K. Lu, "Research on an intelligent solar tracking system based on LPC2131," in Proceedings - 2012 3rd IEEE International Conference on Network Infrastructure and Digital Content, IC-NIDC 2012, 2012.

[2] D. H. Rouvray, "Fuzzy sets and fuzzy logic: Theory and applications," Endeavour, 2003.

[3] J. K. Pepper and N. T. Brewer, "Electronic nicotine delivery system (electronic cigarette) awareness, use, reactions and beliefs: A systematic review," Tobacco Control. 2014.

[4] R. Yuwono, I. Mujahidin, A. Mustofa, and Aisah, "Rectifier using UFO microstrip antenna as electromagnetic energy harvester," Adv. Sci. Lett., 2015.

[5] M. L. October, "Programming Exercise 3: Multi-class Classification and Neural Networks 
Multi-class Classification," October, 2011.

[6] D. Knights et al., "Bayesian community-wide culture-independent microbial source tracking," Nat. Methods, 2011.

[7] J. Lasmono, A. P. Sari, E. Kuncoro, and I. Mujahidin, "Optimasi Kerja Peluncur Roket Pada Robot Roda Rantai Untuk Menentukan Ketepatan Sudut Tembak," JASIEK (Jurnal Apl. Sains, Informasi, Elektron. dan Komputer), 2019.

[8] W.-H. Steeb, "Fuzzy Sets and Fuzzy Logic," in The Nonlinear Workbook, 2012.

[9] I. Mujahidin, S. H. Pramono, and A. Muslim, "5.5 Ghz Directional Antenna with 90 Degree Phase Difference Output," 2018.

[10] J. Kattge et al., "TRY - a global database of plant traits," Glob. Chang. Biol., 2011.

[11] D. Fang, Antenna Theory and Microstrip Antennas. 2011.

[12] I. Mujahidin, R. Yuwono, and A. Mustofa, "Rancang Bangun Rectifier Antenna Mikrostrip Ufo Pada Frekuensi Ultra Wideband (UWB) Sebagai Pemanen Energi Elektromagnetik," J. Mhs. TEUB, vol. 3, no. 2, 2015.

[13] A. N. Putri, "Penerapan Fuzzy Controller Untuk Pergerakan Player Pada Game Engine 3D Berbasis Agen Cerdas," J. Transform., 2017.

[14] T. A. S, A. Rabi', D. Minggu, and I. Mujahidin, "Frequency Hopping Video Real Time Untuk Pengamanan Data Pengintaian Operasi Inteligence TNI," JASIEK (Jurnal Apl. Sains, Informasi, Elektron. dan Komputer), 2019.

[15] M. Abzalov, "Database," in Modern Approaches in Solid Earth Sciences, 2016.

[16] I. Mujahidin and P. S. Arinda, "Antena Compact Double Square Marge 2, 6GHz Dengan Output Perbedaan Fase 90 Derajat Untuk Aplikasi LTE," JEECAE (Journal Electr. Electron. Control. Automot. Eng., vol. 4, no. 2, pp. 273-278, 2019.

[17] S. Sjogelid, Raspberry Pi for Secret Agents. 2013.

[18] I. Mujahidin and B. F. Hidayatulail, "2.4 GHz Square Ring Patch With Ring Slot Antenna For Self Injection Locked Radar," JEEMECS (Journal Electr. Eng. Mechatron. Comput. Sci., vol. 2, no. 2, 2019.

[19] C. Bell, Beginning sensor networks with Arduino and Raspberry Pi. 2013.

[20] M. T. Prakarsa, D. Wahyuni, N. Rachman, and I. Mujahidin, "Optimasi Sistem Komunikasi Dari Ht Dengan Hp Dalam Pelaksanaan Tugas Operasi TNI AD Menggunakan Metode DTMF," JASIEK (Jurnal Apl. Sains, Informasi, Elektron. dan Komputer), 2019.

[21] P. Callahan-Lyon, "Electronic cigarettes: Human health effects," Tob. Control, 2014.

[22] B. F. Hidayatulail and I. Mujahidin, "Potential Of 77, $78 \mathrm{~mW}$ Red Diode Laser For Photodynamic," JEEMECS (Journal Electr. Eng. Mechatron. Comput. Sci., vol. 2, no. 2, 2019.

[23] D. A. Yudhistira and B. Suprianto, "Perancangan Sistem Pengendali Kecepatan Motor Brushless DC Tiga Fasa Menggunakan Kontroler PID-Fuzzy," J. Tek. Elektro, 2017.

[24] S. K. Sugiarto, I. Mujahidin, and A. B. Setiawan, "2, $5 \mathrm{GHz}$ Antena Mikrostrip Polarisasi Circular Model Patch Yin Yang untuk Wireless Sensor," JEECAE (Journal Electr. Electron. Control. Automot. Eng., vol. 4, no. 2, pp. 297-300, 2019.

[25] M. F. Rahmat and M. Md Ghazaly, "Performance Comparison Between PID and Fuzzy Logic Controller In Position Control System Of DC Servomotor," J. Teknol., 2013.

[26] I. Mujahidin, "DIRECTIONAL $1900 \mathrm{MHz}$ Square Patch Ring Slot Microstrip Antenna For WCDMA," JEEMECS (Journal Electr. Eng. Mechatron. Comput. Sci., 2019.

[27] M. A. R. Arif Rahman Hakim, Sumardi, "Kontrol Posisi Pada Sistem Pergerakan Mobile Robot Kinematic," Article, 2015.

[28] M. R. Setiawan, M. A. Muslim, and D. Nusantoro, "PID Menggunakan Visual Basic 6 . 0 Dan," EECIS, 2012. 